
\title{
28 Research Square \\ Evaluation of School Mental Health Promotion Program: A Qualitative Study
}

\author{
Mitra Borji \\ Iran University of Medical Sciences \\ Iran University of Medical Sciences

\section{Ahmad Hajebi}

\section{Asal fazeli} \\ Allameh Tabataba'i University

\section{Zahra khorrami} \\ Iran University of Medical Sciences

\section{Helia Ranjbar} \\ University of Tehran

\section{Amirali Hajebi} \\ Tehran University of Medical Sciences
}

Morteza Naserbakht ( $\nabla$ mnaserbakht@gmail.com )

*Research Center for Addiction and Risky Behavior (ReCARB), Iran University of Medical Sciences

\section{Research Article}

Keywords: Evaluation, Mental Health, Promotion, School

Posted Date: September 2nd, 2022

DOI: https://doi.org/10.21203/rs.3.rs-1331860/v2

License: (c) (i) This work is licensed under a Creative Commons Attribution 4.0 International License.

Read Full License 


\section{Abstract \\ Background}

Due to the need to identify problems related to mental health among students and their proper management by offering specialized medical services to them, recently a relevant research project has been fully implemented in schools of all grades in Iran. Since the only way to measure the effectiveness and find the strengths and weaknesses of a program is to evaluate it, the present study aims to monitor and evaluate the mentioned project in order to improve the quality of project implementation, identify defects and shortcomings and upgrade the existing system.

\section{Methods}

The present study was a qualitative study using conventional content analysis that used a semistructured in-depth interview to obtain information from a group of stakeholders. Selected instructors, teachers, principals, and designers of the School Mental Health Promotion Program were the target of the study.

\section{Results}

The findings of the present study were presented in four categories of program strengths, program weaknesses, factor the s preventing achievement of program objectives and recommendations for program improvement. It is to be noted that 14 subcategories were also devised, and finally, 50 codes were extracted. The overall results of the evaluation of the School Mental Health Program showed its effectiveness.

\section{Conclusions}

The new and practical the model of School Mental Health Program has opened a new perspective to school-based interventions. However, the expectation of full implementation and continuation of this program in the short term and with limited resources does not seem very realistic because making change is often challenging and fraught with problems and obstacles.

\section{Introduction}

Due to the prevalence of mental illness in children and adolescents, which is one of the growing global problems (1), as well as insufficient services in this regard, promotion of mental health in this population seems necessary (2). Research showed that most mental health problems occur during adolescence and early adulthood, with more than half starting before the age of 16 Such as schizophrenia, phobia, and separation anxiety disorder. However, at the time, these problems were either unrecognized or not 
adequately supported. Nearly half of all psychiatric disorders diagnosed in adulthood actually begin in childhood and adolescence. The younger the age of onset of the disorder, the higher the severity and persistence of the disorder and the more resistant it is to treatment (3). In recent years, the prevalence of mental illness in Iran has been on the rise. This indicates the need to pay attention to the effectiveness of existing interventions and adopt strategies to manage these conditions (4). Given the importance of childhood and adolescence in creating mental health and preventing mental health problems, school is a unique resource to help with this. Schools can help identify and address significant mental health problems in children and adolescents. About 25 percent of children and young people in the developed world have an identifiable mental health problem, and of those 25 percent, 10 percent have the criteria for a disorder. Another reason why schools are so important to mental health is that it provides an opportunity for mental health interventions, and research in the last two decades has shown this to be the case (5).

Furthermore, schools can promote positive mental health, provide resources for the development of the child or young person, and help them cope with negative stress in stressful or challenging situations Another critical point is the important role of the school in helping people for whom the family and the environment are less supportive (5). Schools are at the forefront of promoting positive mental health. This is an important way to deal with the growing prevalence of mental disorders around the world (1). Teacher education is recognized as an effective intervention in mental health in school settings, promoting positive mental health, and a sense of solidarity among stakeholders and facilitating students' learning, thus improving the overall school environment. Teachers 'educational interventions have significantly improved their awareness and attitude mental health and better identification of children and adolescents with mental health problems (2). Increased knowledge, decreased stigma, and selfconfidence in providing student-to-student support peer, as well as direct positive effects on students in a cluster-randomized trial on mental health education at primary schools was observed (6). In addition, mental health education in schools helps teachers to reduce stress and feel more satisfied with their role which proved to be economical (7). Literally, there are so many mental health interventions designed for schools around the world, some of which have been evaluated e.g. "mental health", "emotional social learning", "emotional literacy", "emotional intelligence", "resilience", "life skills" and "personality training" (8).

Therefore, due to the need to identify problems related to mental health among students and their proper management by offering specialized medical services to them, recently a relevant research project has been fully implemented in schools of all grades in Iran. The research project, entitled the School Mental Health (SMH) Program, is evidence-based and its protocol is published in the form of a handbook. The handbook is approved by all member states of the World Health Organization in the Eastern Mediterranean Region. It denotes cost-effective strategies that can be implemented on large scale and includes key principles for changing assignments for people who are somehow involved in the training process engaging the non-specialist workforce. 
Determining the success rate of this program in achieving its intended goals is the next step in the full implementation of the program (9). Unfortunately, participation of adolescents and their caregivers in mental health services in schools was low and this was despite early identification of problems by school staff, access to SMH providers and their attendance at school, and basic evidence-based school interventions. Also based on research about $70 \%$ of young people and caregivers end SMH services prematurely (10). However, studies for School Mental Health evaluation showed this project's effectiveness led to increased academic performance, school attendance, more adaptive behavior among students and reduced violence in schools, and reduced referrals for specific instruction among students significantly $(11,12)$.

Behavioral interventions could be both school-centered (13) and effective in reducing behaviors such as self-harm, aggression, disciplinary problems, and behavioral conflicts $(14,15)$. In light of the above, the present study aimed at reviewing the project in order to spot the gaps and formulate recommendations to address them. As well as an assessment of its effectiveness.

\section{Method}

The present study was a qualitative study using conventional content analysis that used a semistructured in-depth interview and FGD to obtain information from groups of stakeholders. Selected instructors, teachers, principals, and designers of the School Mental Health Promotion Program were the target of the study. Purposeful sampling was used in this study. In this study, a total of 4 group discussion sessions were held with school teachers. The duration of each session was expected to be 4560 minutes, which was done according to the saturation of the discussions and the desire of the participants to continue the discussion, increased or decreased. The median experience of teaching in these teachers in these 4 groups was 8 years. The average age of the teachers was $33 \pm 8$ years. $48 \%$ of the participants in these group discussion sessions were male and $52 \%$ were female. As mentioned earlier, in-depth interviews were also used in another part of the study to collect information. Each interview was conducted only once which lasted from 14 to 60 minutes In-depth interview sessions were conducted with 3 school principals, 3 school counselors, 2 psychologists of the counseling core in the regional education headquarters, as well as 2 school mental health planners. In order for the subjects to be able to fully explain their understanding and experiences, the questions were asked in an open form and then continued according to the discussion process. These open questions allowed the participants to share their opinions, perceptions, and experiences and Express themselves. Interviews were held at the interviewees' workplaces where calmness and the absence of disturbing factors were observed. Interview questions were compiled according to the goals of the literature review. Some of the main questions include "What are the strengths and weaknesses of this program in your design and implementation stages? "What do you think threatens the implementation and continuation of the program?" and "If you were involved from the beginning in the program design, how would you modify it?

The interviews were all recorded and transcribed and notes were taken during the interviews. The interviews continued until the saturation was reached so that no new code was found. The transcribed 
text of each interview was considered as an analysis unit and was analyzed in five stages according to the Graham and Landman model: at least 2 authors (MB and $\mathrm{MN}$ ) read them. Following model 1- they read the text several times to understand its general meaning. 2- They divided the text into semantic units, containing the concepts and meaning extracted from the text. 3- At this stage, the codes, which were the labels of semantic units, were created by condensing and shortening them but maintaining their original core. 4- The codes were put together based on content similarities and then subthemes were created. 5 . Finally, classes were created that made the basis for the content that was placed in the next them. Because qualitative analysis requires a circular process, we went back many times to complete the steps (16). The participants did not review the originally transcribed text of the interviews and results, but the researchers considered their final comments and notes from the interview after each meeting, and two people did the whole process. Data was also managed manually without using any software. To clarify the codes and classes, direct quotes from the interviews were provided in the results section.

The accuracy and validity of the data were assessed according to the criteria of Goba and Lincoln (17), which were examined in the following cases: 1 . Long term engagement by the researcher with the topic of study, 2. Following the review by a colleague, the coding was done by two people, then, the external check of codes was done by the article authors, and some codes were corrected. Moreover, after performing steps 4 and 5, the analysis was reviewed by the first and corresponding authors. Other authors also monitored all stages and commented when necessary. 3 . Triangulation of data sources conducted by interviewing various groups to examine their views. 4- Searching for conflicting evidence using purposeful sampling of those who might suggest conflicting views to give a full description of the subject.

Accordingly, a pilot project, according to the above-mentioned published handbook, has been implemented in schools after translation and customization. This guidebook was initially designed initially for those involved in the learning process, including teachers, administrators, health educators, counselors, and education policymakers. The handbook includes information to increase teachers' awareness about the importance of mental health in schools, the developmental and psychological stages of children, and strategies for managing children's age-appropriate behavior. It also familiarizes teachers with the symptoms of psychiatric disorders in students (mental health literacy) and their distinction from abnormal mood disorders (18).

The pilot project was designed to initially select two instructors from each school who were counselors, health instructors, or other school staff. A total of 6 schools were selected and the age of students was between 6 and 17 years. They took a three-day training course and were trained as trainers of trainers. Then they trained the school teachers who began identifying and referring students with symptoms of emotional, psychological, and behavioral disorders. In cases the teachers themselves could solve a student's problems with a minor intervention, they would not refer them to the selected instructor or school counselor. The selected instructors or school counselor intervened based on their specialty; otherwise, the students were referred to the Education Counseling Center. The center was staffed with experts from various fields to visit these students and refer them to a psychiatrist if needed. The feedback process was based on Figure 1 from the psychiatrist to the counseling core, from the counseling core to 
the selected instructors, and from the instructor-to-the teacher. The project's ethical considerations included the possibility of withdrawing from the study at any stage, the confidentiality of information, and anonymous dissemination of the results.

\section{The Findings}

The findings of the present study were presented in four themes 1) program strengths (Table 1),2) program weaknesses (Table 2), 3) factors preventing the achievement of program objectives (Table, 3 ) and 4) recommendations for program improvement (Table 4). It is to be noted that 14 subcategories were also devised, and finally, 50 codes were extracted.

\section{1-Strengths}

Table 1: The theme of strengths and its subcategories and codes

\begin{tabular}{|c|c|c|}
\hline theme & Subtheme & Code \\
\hline \multirow[t]{12}{*}{ Strengths } & \multirow[t]{2}{*}{ Educational benefits } & Useful educational resources \\
\hline & & Promoting and correcting teachers' attitudes \\
\hline & \multirow[t]{4}{*}{ Design differentiation } & Conflicts and involvement of school staff \\
\hline & & Increase counseling demands on education \\
\hline & & Model of using selected trainers \\
\hline & & Matching needs \\
\hline & \multirow[t]{4}{*}{ Design efficiency } & Teachers' satisfaction with the plan \\
\hline & & Comprehensive design \\
\hline & & Reducing teachers' improving classroom management \\
\hline & & $\begin{array}{l}\text { Increasing individual motivation and creating positive } \\
\text { challenges for selected educators counselors }\end{array}$ \\
\hline & \multirow{2}{*}{$\begin{array}{l}\text { Positive consequences of } \\
\text { program implementation }\end{array}$} & Reducing stigma \\
\hline & & $\begin{array}{l}\text { Ability to identify psychiatric disorders and refer } \\
\text { students to a specialized level }\end{array}$ \\
\hline
\end{tabular}

\section{* Educational benefits}

Teaching mental health topics to help teachers understand the importance of mental health in schools, raise awareness about the developmental stages of children's mental development, provide strategies for managing age-appropriate behavioral management, including mental organization and management of undesirable behaviors, thorough understanding of methods of promoting mental health in schools, 
familiarizing students with the symptoms of psychiatric disorders and distinguishing them from normal mood disorders, providing appropriate interventions for a variety of mental health problems and psychiatric disorders. One of the events that were expected to take place directly in teacher training was that teachers' attitudes toward students' mental disorders and behavioral problems changed. In an interview with teachers, they said that education had changed their views.

"The course has made us a little more open, a little more focused on some kids." Or another teacher insisted, "My knowledge has increased tremendously, and I've found that in some places, I'm wrong in class after 25 years as a teacher."

\section{* Design presentation model}

One of the occasions that were more prominent for the presenters and designers in this project was the selection of instructors as liaisons and counselors in schools. What distinguishes this project from other implemented projects? As the No. 1 designer puts it:

"One of the strengths of empowerment was, raising the sense of responsibility in the selected instructors and their strong commitment, which was the basis for these interventions in schools."

\section{* Effective design}

Doing so had increased teachers' skills in identifying and referring students, which in turn led to less energy for behavioral problems and paying more attention to subjects.

"When a student is referred to work with the counselor, this time, our educational efficiency increases as we have to spend less energy on such students."

\section{2-Weaknesses}

Table 2: The theme of weaknesses and its subcategories and codes 


\begin{tabular}{|lll|}
\hline Theme & subtheme & code \\
\hline \multirow{3}{*}{ Weaknesses } & Lack of family training & Family education \\
\cline { 2 - 3 } & Reference and feedback & Referring to higher levels \\
& Cores with insufficient power \\
& Response structure and feedback \\
& Registration and reporting \\
\hline & Designing support process \\
\cline { 2 - 2 } & Coordination between design components \\
\cline { 2 - 2 } & Selection of pilot schools \\
\hline Lack of workforce & Limitations of selected coaches \\
\hline
\end{tabular}

\section{* Lack of family education}

Lack of family education was one of the factors that made it difficult to achieve the project goals. It seems that if educational programs were held for families in the area, in addition to being welcomed, it would encourage them to come back and follow their student's status.

"I think the issue of families is a gap in this project".

* Reference and feedback

Feedback is not provided in a proper manner, which seems to be due to the performance of the service providers, including overcrowding and lack of mastery. One of the school principals stated that:

"We have to have feedback; we don't get specialized results".

\section{* Structural problems}

The project has been hampered by problems such as the selection of pilot schools and low financial support from other agencies and organizations.

\section{* Lack of manpower}

It seems that the number of selected instructors should be increased due to the large volume of work. Lack of adequate time and expertise of selected teachers in schools were among their limitations. One of the consultants at the educational counseling center stated that:

"The selected trainers were people who had 1) not enough time, 2) lack of expertise and 3) that, like a social worker, did not have a wide field of work." 
Table 3: The theme of factors preventing the achievement of the project goals and its subcategories and codes

\begin{tabular}{|c|c|c|}
\hline Theme & Subtheme & code \\
\hline \multirow{7}{*}{$\begin{array}{l}\text { Factors preventing the achievement } \\
\text { of the project goals }\end{array}$} & \multirow[t]{2}{*}{ Beneficiary } & Students' financial problems \\
\hline & & Lack of follow-up by families \\
\hline & \multirow[t]{4}{*}{$\begin{array}{l}\text { Factors related } \\
\text { to teachers }\end{array}$} & $\begin{array}{l}\text { Teachers' workload and increasing their } \\
\text { responsibilities }\end{array}$ \\
\hline & & Teachers' burnout \\
\hline & & Teachers' time limitation \\
\hline & & $\begin{array}{l}\text { Lack of teamwork and cooperation of } \\
\text { some teachers }\end{array}$ \\
\hline & $\begin{array}{l}\text { Legal } \\
\text { limitations }\end{array}$ & $\begin{array}{l}\text { Structural problems of the execution field( } \\
\text { Ministry of education) }\end{array}$ \\
\hline
\end{tabular}

The field of mental health requires a general culture that should be implemented in a variety of ways, including public education, the education of influential people, and self-care or other methods. The financial problem of students in paying for counseling fees at the Education Counseling Center was one of the factors that prevented families from following up. Since some of the specialized services at the counseling center were provided by informal forces, families had to pay their fees. The two causes of fear of stigma and financial problems of families were the reason for the lack of referral or non-follow-up treatment. One of the selected instructors said:

"The problem in the treatment process is that the families don't cooperate, or if they do, it's not continuous, and also they don't go for treatment and there is a fear of stigmatization."

\section{4- Recommendations for program improvement}

Table 4: The theme of recommendations for program improvement and its subcategories and codes 


\begin{tabular}{|c|c|c|}
\hline Theme & Subtheme & code \\
\hline \multirow{22}{*}{$\begin{array}{l}\text { Recommendations for } \\
\text { program improvement }\end{array}$} & \multirow[t]{7}{*}{ Education } & Educational support \\
\hline & & Expanding educational resources \\
\hline & & Teaching how to write reports \\
\hline & & Teaching students and families \\
\hline & & Changing the structure of education \\
\hline & & Continuing education and retraining \\
\hline & & Applied and need-based training \\
\hline & \multirow{10}{*}{$\begin{array}{l}\text { Design and structure } \\
\text { of the program }\end{array}$} & Financing \\
\hline & & Prioritizing primary education \\
\hline & & Establishing a program and continuing it \\
\hline & & Special and specific time \\
\hline & & The need for a school counsellor \\
\hline & & Integration into school programs \\
\hline & & School management role \\
\hline & & $\begin{array}{l}\text { The need to pay attention to all levels of } \\
\text { education }\end{array}$ \\
\hline & & $\begin{array}{l}\text { Collaborating with other governmental } \\
\text { agencies }\end{array}$ \\
\hline & & $\begin{array}{l}\text { A comprehensive approach to students' } \\
\text { psychological problems }\end{array}$ \\
\hline & \multirow[t]{3}{*}{ Empower Specialists } & Counseling core \\
\hline & & Social workers \\
\hline & & Empowering each teacher \\
\hline & \multirow[t]{2}{*}{ To fulfill Expectations } & $\begin{array}{l}\text { Considering incentives for selected } \\
\text { educators and teachers }\end{array}$ \\
\hline & & $\begin{array}{l}\text { Lack of inappropriate behavior by } \\
\text { teachers }\end{array}$ \\
\hline
\end{tabular}

\section{* Training}

Regarding teacher training course/methodology, there was a call for a change in the educational structure of the program to empower teachers so that experts can train teachers and not selected instructors to provide more specialized and quality training, as well as training students and families. 
"Keep in mind that these teachings are very effective for children and teachers, as well as parents."

\section{* Program design and structure}

Currently, in the first year of high school, people are working as counselors to provide services to students. But primary and secondary schools do not have counselling experts. Restrictions on counselling centers and their experts in the Ministry of education require solutions to be devised to meet the students' needs, especially in primary schools. One of the requests of the school staff was to have a school counsellor.

"We really need to have one person on the subject of psychology in every school."

\section{* Specialists}

Although the role of selected instructors is to perform executive work and counselling, and it was intended to track students' mental status as well as provision of some support services, it seems that rehabilitating the mentally ill as well as supporting them and their families is a specialized task and the presence of a social worker will improve the service.

"First, the specialists must be identified. More specialists must enter the setting to be able to cover services, for example, a social worker."

\section{* Factors of the project success}

Considering incentives for selected teachers and educators can be useful in increasing their motivation as well as the results of interventions and project implementation.

"If these efforts are made together, well, they will naturally work better."

\section{Discussion}

The present study evaluated the School Mental Health Program, and since the research in this field is small and vague, we examined the mentioned topics using the stakeholders' perspectives. These perspectives are a strategic tool that can be used to understand the behaviors, intentions, relationships, and interests of individuals and organizations to produce knowledge about them, and to identify current and future opportunities and threats (19). The evaluation findings were reported in four categories, which include: 1. Strengths with subcategories of educational benefits, design differences, and design efficiency, 2. Weaknesses and its subcategories include educational shortcomings, referral and feedback, structural problems, and lack of workforce, 3 . Factors preventing the achievement of the project goals and its subcategories including stakeholders, teachers, and legal constraints, and 4. Recommendations for program improvement and its subtheme include training, program design and structure, specialists, and expectations.

School-centered interventions mostly involved school members and provide a natural context for primary interventions. The selected model, i.e. the selection of chosen instructors in schools and their training, as 
well as refresh-training and supervisory sessions along with involving school principals and teachers to gain their support and cooperation in carrying out the project, facilitated the achievement of the primary goals and expectations. The results of the study showed that the interventions led to the empowerment of teachers and educators in these schools for identifying students' psychiatric disorders compared to pre-intervention status. It also yielded other results, such as reducing teachers' burnout and improving classroom management, as well as changing their attitudes toward students' psychological problems. Studies have shown that trained teachers have a high potential to participate in the provision of mental health services and that educational interventions in the group of teachers who were not trained have been able to improve teachers' attitudes toward identifying and referring students (20). The teacher, more than any other specialist in the school, is in a position to identify students, communicate with them on a daily basis, and build a relationship based on trust and mutual respect. Thus, the teacher is at the forefront of mental health programs that are in direct contact with students (21). A systematic review of 49 studies found that teachers played an essential role in the mental health professional team, such as psychologists (22). Factors that prevent the achievement of the project goals were: financial problems and lack of education of students and their families for seeking counseling, the quality of counseling services at the core of counseling (lack of expertise in various fields and lack of feedback to lower levels), the high workload of some teachers and time constraints of the selected trainers.

The results of the study showed that young teachers were more motivated to participate in the project, and retired teachers less. This indicated that some schools, especially non-governmental schools that have retired education staff, will not be a suitable environment for such an intervention, and the implementation format should be different. One of the limitations of this plan was the lack of attention to family education and their justification for participation and follow-up. In addition to educating families, educating students based on their abilities at different grades is recommended. Moreover, empowering all students, whether they have a problem or not, increases their ability to recognize and diagnose psychiatric symptoms and problems, and of course, seek help in service centers earlier (counseling centers) and prevent more severe problems. The results of the Kratochwill study showed that close collaboration and communication between families and school staff during one year of intervention reduced violent behavior and led to greater adaptability among students with behavioral problems than in the control group (23). In a review of 34 studies conducted in schools around the world to reduce psychological problems such as determination, depression and anxiety, Greenberg et al., concluded that the interventions in which school and family participated together had the most impact and efficiency. Moreover, programs that focused on multiple target groups (such as individuals, families, and school staff) and combination programs that focused on behavioral changes of students, teachers, families, and relationships between school, family, and other social institutions were the most influential (24).

The results of a study by Durlak et al. showed that student-centered education and interpersonal problemsolving training, as well as school change strategies, had the most significant effect on improving students' mental health (25). Specific interventions in schools, such as the frequency and continuity of interventions, having purposeful outcomes, and parental involvement, can affect teachers' motivation and quality performance of interventions (26).

Page 12/17 
Considerations/recommendations for improving the program:

Modifications to some rules and regulations in education, feedback, and appropriate responses from specialized levels (counselling centers and community-based mental health centers) to lower levels. Improving enrollment and reporting, continuous and gradual retraining, lack of intensive training, coordination of all project members, including teachers, educators, counselling centers, considering incentives for the positive performance of teachers and educators are also recommended.

Among the recommendations made one is that the project results should continue and the participation of all stakeholders should be sought and supported for its sustainability. A study by Green Burke et al. showed that programs that have been followed up regularly for several years had far better effects than short-term programs (24). Another suggestion was for schools to connect with other agencies to benefit from their services if needed. In some developed countries, the "Expanded School-based Mental Health" was developed in the early 1990s to promote mental health. In this project, schools were closely related to health center centers, hospitals and universities, and by providing diagnostic, treatment, prevention and evaluation programs, they promoted the students' mental health (27).

Interviewers found the presence of counsellors in schools very important. During their research, Durlak et al. concluded that although teachers are service providers in schools, many feel that school counsellors should play a greater role than teachers in these programs (28). Teachers said the need to retrain mental health issues and increase their mental health literacy was another factor for influencing the success of the program. In a study by Gibson et al., many teachers reported limited and incomplete training in behavioral interventions (29). Prioritizing primary education comprehensively was another suggestion made by the interviewees. In a systematic review of studies on the School Mental Health Program, Sutan et al. concluded that reducing students' mental health problems were more effective through behavioral changes at a younger age and in early childhood (30).

\section{Conclusion}

The overall results of the evaluation of the School Mental Health Program showed its effectiveness. The new and practical model of the School Mental Health Program has opened a new perspective on schoolbased interventions. However, the expectation of full implementation and continuation of this program in the short term and with limited resources does not seem very realistic because making change is often challenging and fraught with problems and obstacles. Change in organizations is more complex and requires resources, facilities, expertise, and time. Therefore, by foreseeing and drawing a broad and appropriate outlook, while realistically recognizing the situation, proper steps should be planned and implemented to organize the establishment of mental health services in schools.

\section{Abbreviations}




\section{Declarations}

\section{Ethics approval and consent to participate}

The interviewee first gave a brief explanation of the research and its objectives to the participants. Then verbal consent was obtained to participate in the study. And they all started the interview after making sure they were ethical. All methods were carried out in relevant regulations and guidelines. This study was approved by Biomedical Research Ethics Committee. The authors of the article conducted all interviews by making a call a number of participants, including program designers, executers, instructors and teachers arrange a meeting. In addition the information on the subject of study, its objectives, and the identity of the researchers was provided by phone.

\section{Consent for publication}

Not applicable.

\section{Availability of data and materials}

The datasets generated and analyzed during the current study are not publicly available due privacy, confidentiality and cultural reasons, but are available from the corresponding author on reasonable request.

\section{Competing interests}

The authors declare that they have no competing interests.

\section{Funding}

None.

\section{Authors' contributions}

M.N. and A.H. and H.R. identified the research question and designed the study. M.B. and Z.KH. And AA.H. and A.F. analyzed the data and contributed to writing the manuscript. All authors read and approved the final manuscript.

\section{Corresponding authors}

Correspondence to Morteza Naserbakht and Ahmad Hajebi

\section{Acknowledgements}


The authors of the article would like to express their gratitude to the esteemed Director General of the Department of Mental Health and Substance Abuse of the Ministry of Health and Medical Education, the Head of the Ministry of Education, and the principals and teachers of the selected schools.

\section{References}

1. O'Reilly M, Svirydzenka N, Adams S, Dogra N. Review of mental health promotion interventions in schools. Social psychiatry and psychiatric epidemiology. 2018; 53(7):647-62. https://doi.org/10.1007/s00127-018-1530-1

2. Imran N, Rahman A, Chaudhry N, Asif A. World Health Organization "School Mental Health Manual"based training for school teachers in Urban Lahore, Pakistan: study protocol for a randomized controlled trial. Trials. 2018; 19(1):290. https://doi.org/10.1186/s13063-018-2679-3

3. Chisholm KE, Patterson P, Torgerson C, Turner E, Birchwood M. A randomised controlled feasibility trial for an educational school-based mental health intervention: study protocol. BMC psychiatry. 2012; 12(1):23. https://doi.org/10.1186/1471-244X-12-23

4. Noorbala AA, Damari B, \& Riazi IS. Evaluation of mental disorders incidence trend in Iran. Daneshvar Medicine. 2014; 21(112). https://www.sid.ir/en/journal/ViewPaper.aspx?id=444366

5 . Weare K, Nind M. Mental health promotion and problem prevention in schools: what does the evidence say? Health promotion international. 2011; 26(suppl_1):i29-i69. https://doi.org/10.1093/heapro/dar075

6. Jorm AF, Kitchener BA, Sawyer MG, and Scales H, Cvetkovski S. Mental health first aid training for high school teachers: a cluster randomized trial. BMC psychiatry. 2010; 10(1):51. https://doi.org/10.1186/1471-244X-10-51

7. Weist MD, Murray M. Advancing school mental health promotion globally. Advances in School Mental Health Promotion. 2011; 1(sup1):2-12. https://doi.org/10.1080/1754730X.2008.9715740

8. Weare K. Mental health and social and emotional learning: Evidence, principles, tensions, balances. Advances in school mental health promotion. 2010;3(1):5-17. https://doi.org/10.1080/1754730X.2010.9715670

9. Tyler RW. Basic principles of curriculum and instruction: Syllabus for Education 305: University of Chicago Press; 1959.

10. Becker KD, Park AL, Boustani MM, Chorpita BF. A pilot study to examine the feasibility and acceptability of a coordinated intervention design to address treatment engagement challenges in school mental health services. Journal of school psychology. 2019; 76:78-88. https://doi.org/10.1016/j.jsp.2019.07.013

11. Jennings J, Pearson G, Harris M. Implementing and maintaining school-based mental health services in a large, urban school district. Journal of School Health. 2000; 70(5):201-5. https://doi.org/10.1111/j.1746-1561.2000.tb06473.x 
12. Nabors LA, Reynolds MW. Program evaluation activities: Outcomes related to treatment for adolescents receiving school-based mental health services. Children's Services: Social Policy, Research, and Practice. 2000; 3(3):175-89. https://doi.org/10.1207/S15326918CS0303_4

13. Ross SW, Horner RH. Bully prevention in positive behavior support: Preliminary evaluation of third-, fourth-, and fifth-grade attitudes toward bullying. Journal of Emotional and Behavioral Disorders. 2014; 22(4):225-36. https://doi.org/10.1177/1063426613491429

14. Lynch D, Keenan M. The good behaviour game: Maintenance effects. International Journal of Educational Research. 2018; 87:91 - 9. https://doi.org/10.1016/j.ijer.2016.05.005

15. Wallace MD, Iwata BA, Hanley GP, Thompson RH, Roscoe EM. Noncontingent reinforcement: A further examination of schedule effects during treatment. Journal of applied behavior analysis. 2012; 45(4):709-19. https://doi.org/10.1901/jaba.2012.45-709

16. Graneheim UH, Lundman B. Qualitative content analysis in nursing research: concepts, procedures and measures to achieve trustworthiness. Nurse education today. 2004; 24(2):105-12. DOI: 10.1016/j.nedt.2003.10.001

17. Tabatabaee A, Hasani P, Mortazavi H, Tabatabaeichehr M. Strategies to enhance Rigour in qualitative research. Journal of North Khorasan University of Medical Sciences. 2013; 5(3):663 - 70. DOI: 10.29252/jnkums.5.3.663

18. Hamoda H. Manual of School Mental Health: World Health Organization, Eastern Mediterranean Regional Office. 2016.

19. Varvasovszky Z, Brugha R. A stakeholder analysis. Health policy and planning. 2000; 15(3):338-45. https://doi.org/10.1093/heapol/15.3.338

20. Kaveh MH, Shojaeezadeh D, Shahmohammadi D, Eftekhar Ardebili H, Rahimi A, Bolhari J. Teachers' role in elementary school mental health: results of an interventional study. Payesh. 2003; 2 (2):101109. 20.1001.1.16807626.1382.2.2.2.3

21. Mental health promotion for schoolchildren: A manual for schoolteachers and school health workers (limited distribution). WHO, Regional Office for the Eastern Mediterranean: Alexandria, Egypt. 1998. https://apps.who.int/iris/handle/10665/116280

22. Franklin CG, Kim JS, Ryan TN, Kelly MS, Montgomery KL. Teacher involvement in school mental health interventions: A systematic review. Children and Youth Services Review. 2012; 34(5):973-82. http://www.sciencedirect.com/science/article/pii/S0190740912000503

23. Kratochwill TR, McDonald L, Levin JR, Scalia PA, Coover G. Families and schools together: An experimental study of multi-family support groups for children at risk. Journal of school Psychology. 2009; 47(4):245-65. https://doi.org/10.1016/j.jsp.2009.03.001

24. Greenberg MT, Domitrovich C, Bumbarger B. The prevention of mental disorders in school-aged children: Current state of the field. Prevention \& treatment. 2001; 4(1):1a.https://doi.org/10.1037/1522-3736.4.1.41a

25. Durlak JA, Wells AM. Primary prevention mental health programs for children and adolescents: A meta-analytic review. American journal of community psychology. 1997; 25(2):115 - 
52.https://doi.org/10.1023/A:1024654026646

26. Egan TE, Wymbs FA, Owens JS, Evans SW, Hustus C, Allan DM. Elementary school teachers' preferences for school-based interventions for students with emotional and behavioral problems. Psychology in the Schools. 2019; 56(10):1633-53. https://doi.org/10.1002/pits.22294

27. Weist MD, Goldstein J, Evans SW, Lever NA, Axelrod J, Schreters R, et al. funding a full continuum of mental health promotion and intervention programs in the schools. Journal of Adolescent Health. 2003; 32(6):70-8. https://doi.org/10.1016/S1054-139X (03)00067 - 3

28. Durlak JA, Weissberg RP, Dymnicki AB, Taylor RD, Schellinger KB. The impact of enhancing students' social and emotional learning: A meta-analysis of school-based universal interventions. Child development. 2011; 82(1):405-32. https://doi.org/10.1111/j.1467-8624.2010.01564.x

29. Gibson JE, Stephan S, Brandt NE, Lever NA. Supporting teachers through consultation and training in mental health. InHandbook of school mental health 2014 (pp. 269-282). Springer, Boston, MA. https://doi.org/10.1007/978-1-4614-7624-5_20

30. Sutan R, Nur Ezdiani M, Muhammad Aklil A, Diyana M, Raudah A. Systematic Review of SchoolBased Mental Health Intervention among Primary School Children. J Community Med Health Educ. 2018; 8(589):2161-0711. DOI: 10.4172/2161-0711.100058

\section{Figures}

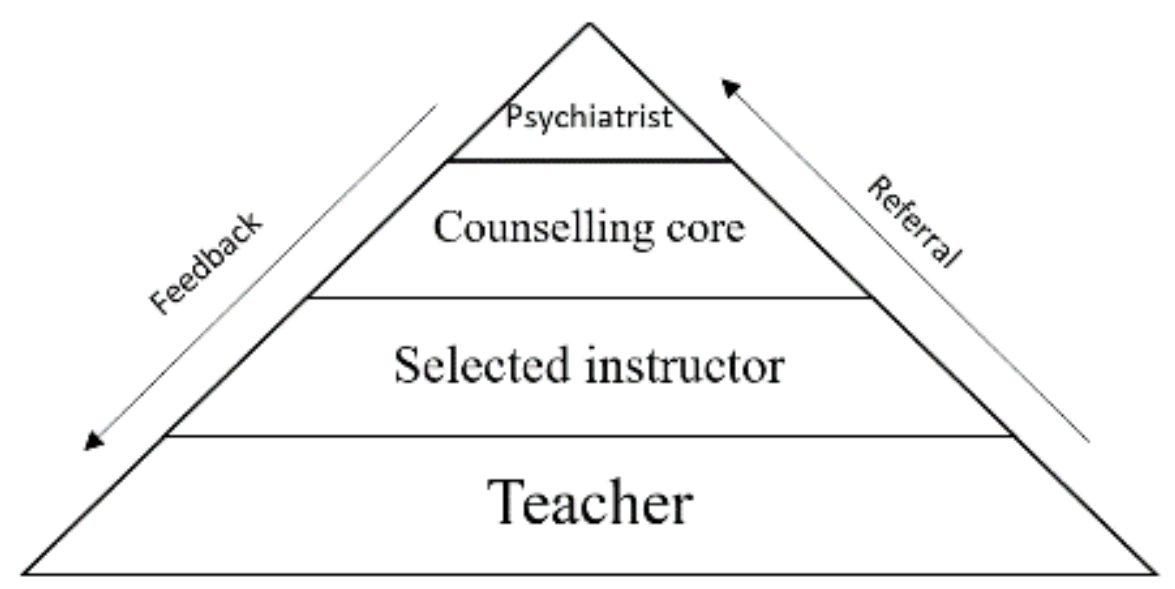

\section{Figure 1}

Model of school mental health pilot project 